\title{
THE ALTERNATION OF PARAPLEGIC PATIENTS MUSCLE PROPERTIES DUE TO ELECTRICAL STIMULATION EXERCISING ${ }^{1}$
}

\author{
By R. Turk, M.D., A. KRalJ, D.Sc., Dipl.Eng., „ T. Bajd, M.Sc., Dipl.Eng., „ \\ M. Štefančič, Ph.D., M.D. and H. Benko, P.T. \\ Rehabilitation Institute, 61000 Ljubljana, Linhartova 51-Yugoslavia and * Faculty of \\ Electrical Engineering, University of Ljubljana, 61000 Ljubljana Tržaška 25-Yugoslavia
}

Abstract. The influence of daily surface electrical stimulation of paraplegic patients' muscles is discussed in the paper. The optimisation of stimulation and training parameters and functionality of retrained muscles when performing erect standing or primitive walking, is discussed.

Key words: Regular electrical stimulation; Disuse atrophied paraplegic patients' muscles; Muscle exercising.

\section{Introduction}

IN the last decade several papers describing results obtained by regular electrical stimulation of de-nervated human musculature/upper motor neuron lesion have been reported. Kralj et al. (1973, 1979) used in their experiments surface stimulation electrodes while Peckham et al. (1976), Wilemon et al. (1967, 1970) and Brindley et al. (1978) used hypodermic needles or surgically implanted electrodes. It is important to state that the results obtained by different researchers are similar despite of different techniques used. Further, one may conclude that the results do not differ much, although different stimulation parameters were chosen. The investigators mentioned started their studies of repeated electrical stimulation of centrally deinervated muscles with the aim to use the exercised muscles for performing functional movements. The group in Ljubljana has started with the same ambitions in 1970 but with a slightly different approach. Our main goal was to demonstrate that the surface stimulation training is effective and that by means of surface stimulation a paraplegic patient can stand up and maintain the erect standing.

The aim of the present report is to discuss and analyse the results obtained in the alternation of paraplegic muscles' properties caused by repeated electrical stimulation exercising. The research was directed towards the problem of finding optimal stimulation and training parameters. This goal has not been reached until now and the papers cited do not stress explicitly this important problem.

\section{Methodology}

Surface electrical stimulation was applied via water taped pad electrodes sized from $5 \mathrm{~cm}^{2}$ to $90 \mathrm{~cm}^{2}$. The electrodes size was selected according to the

1 This work was done at the Rehabilitation Institute and Faculty for Electrical Engineering within the Rehabilitation Engineering Centre of Ljubljana, Yugoslavia, and supported by the Slovene Research Community and the Rehabilitation Services Administration, Dept. HEW, Washington D.C., U.S.A. 
stimulation site (nerve stimulation or direct muscle stimulation) and muscle size. The electrodes were fixed to the extremity with the velcro bands. The large $\mathrm{m}$. gluteus electrodes were stuck on the skin with Medtronic Inc. adhesive tape. Using conductive rubber electrodes, skin irritation occurred because of relatively high stimulating currents. These electrodes are therefore not further used in our programme.

Voltage output stimulator (0-120 V), providing rectangular pulses in the range from $0.05 \mathrm{~ms}$ to I $\mathrm{ms}$ pulse duration and repetition frequencies from Io-60 $\mathrm{Hz}$ was used. The current limit per channel has been set to $30 \mathrm{~mA}$. The resultant muscle force for the chosen stimulation parameters was measured every 2 weeks by means of specially designed joint torque measuring braces. During the electrical stimulation exercising, patients were relaxed or occupied by reading. At the start of the program stimulation sessions of 30 min have been carried out twice daily. Stimulation time was increased for $30 \mathrm{~min}$ per week. Such an approach has been arbitrarily determined to avoid eventual damage to patients' osteoporotic bones. When exercising the atrophied muscles the stimulation had the shape of rectangular trains of stimuli with $4 \mathrm{sec}$ of stimulation and $8 \mathrm{sec}$ of pause.

\section{Patients selection}

Two paraplegic patients have been included up till now in our exercising programme. Patient P. Z. (3I years) had in October 1977 a car accident which caused a T5 complete spinal cord lesion, while P. K. (25 years) suffered in July I978 a complete Tio spinal cord lesion also in a car accident. Patient Z. J. joined our programme in August 1978, and P. K. in January 1979. Both patients were slightly spastic. Having in mind the planned functional experiments of standing and primitive walking the following muscle groups were stimulated in our investigation: ankle joint and plantar flexors and knee extensors of both extremities. Later on we added the hip extensors and abductors.

The patients have been motivated and aware of the program purposes. We have explained to them that this research is an addiction to the standard programme and will only contribute to better condition of their skin, muscles and joints and that they should not expect any other functional advantages.

Every month a complete medical examination was performed with the aim to find changes or to stop the programme if uncontrolled phenomena occurrs. Both patients were also admitted to the standard paraplegia programme at the institute.

\section{Results}

The repeated electrical stimulation exercising has altered the muscles' contractile and mechanical properties. During this investigation only static and dynamic mechanical muscle properties were recorded. Very early in the programme it was demonstrated that isometric exercising is far less effective compared to isotonic. During exercising we used alternate stimulation, e.g. when the right knee performs flexion, the left knee performs extension. We chose such a pattern because of it's similarity to walking. The frequency of stimulation was $20 \mathrm{~Hz}$ and pulse duration $0.3 \mathrm{~ms}$. Continuous electrical stimulation compared with stimulation trains of on-and-off stimulating periods has been established to be less effective. During the sustained stimulation the muscle contraction diminishes in a few minutes (probably due to exhaustion of the transmitter in the junction of the 
motor end-plate and synapse). In this way there is no evident proof whether the muscle is already fatigued.

According to our results published by Kralj et al. (1973) we stop the training programme once the muscle force reaches a certain plateau (saturation level). It seems that plateau can be reached already within one or two months. This point is an important measure for the termination of the exercising programme. The question which is to be solved in the near future is; what is the shortest time for achieving this plateau? Following some observations during our experiment we expect that loading of the exercised extremity can lead to a higher level of obtained muscle force. We believe that a proper loading strategy during the exercising period combined with potimal stimulation parameters will bring an effective and short retraining procedure of disused paraplegic patients' muscles.

The alternations of the joint torque obtained by plantar flexors as a function of stimulation voltage are shown in Figure $\mathrm{I}$. The plateau has been achieved in one month. The variations of the measured results belong to different measurements and are also influenced by electrodes positioning variations. The results in Figure I were obtained without any loading of extremity and by using isotonic exercising.

The lowest fatigue point of the electrically excited muscles was found at low stimulation frequencies. The same has been stated also by other authors. The low stimulating frequency is closer to natural functioning of the muscle. From Figure 2 it can be seen that the minimal decrease of ankle-joint moment, occurs at $20 \mathrm{~Hz}$ stimulation of plantar flexors. The muscle fatigue does not depend

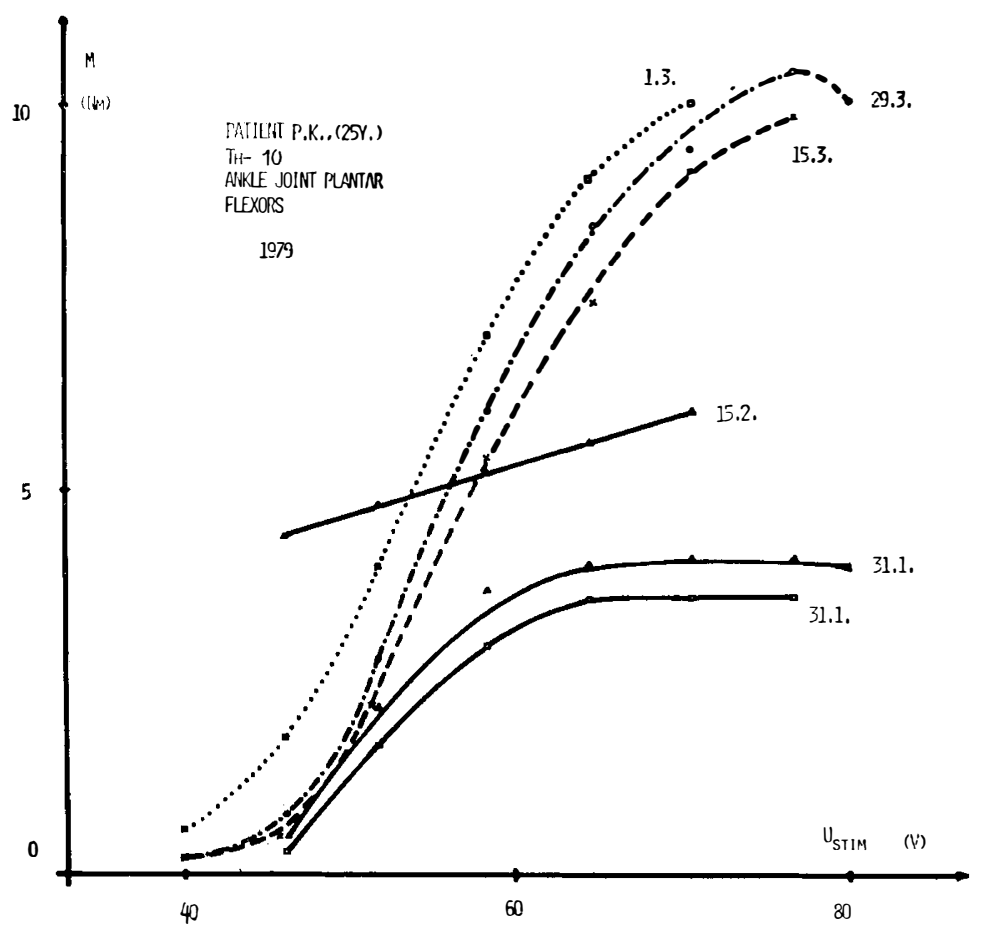

FIG. I

Joint torque versus stimulation amplitude plots showing the effect of the training programme. 


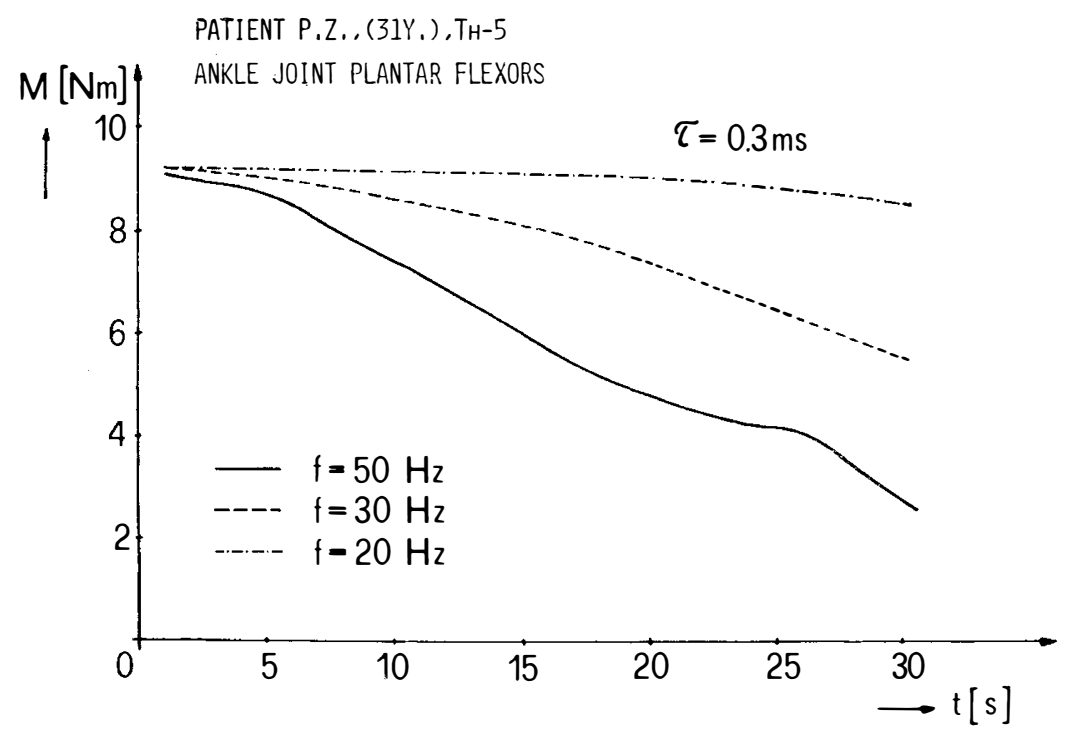

FIG. 2

The joint torque decrease at different stimulation frequencies.

much upon stimulus duration. The dependance of muscle fatigue upon stimulation frequency behaves in the similar manner with both paraplegic patients selected for our ${ }_{1}$ programme. From Figure 3 it can be seen that also the properties of normal subject's muscle do not differ much from the retrained paraplegic patient's

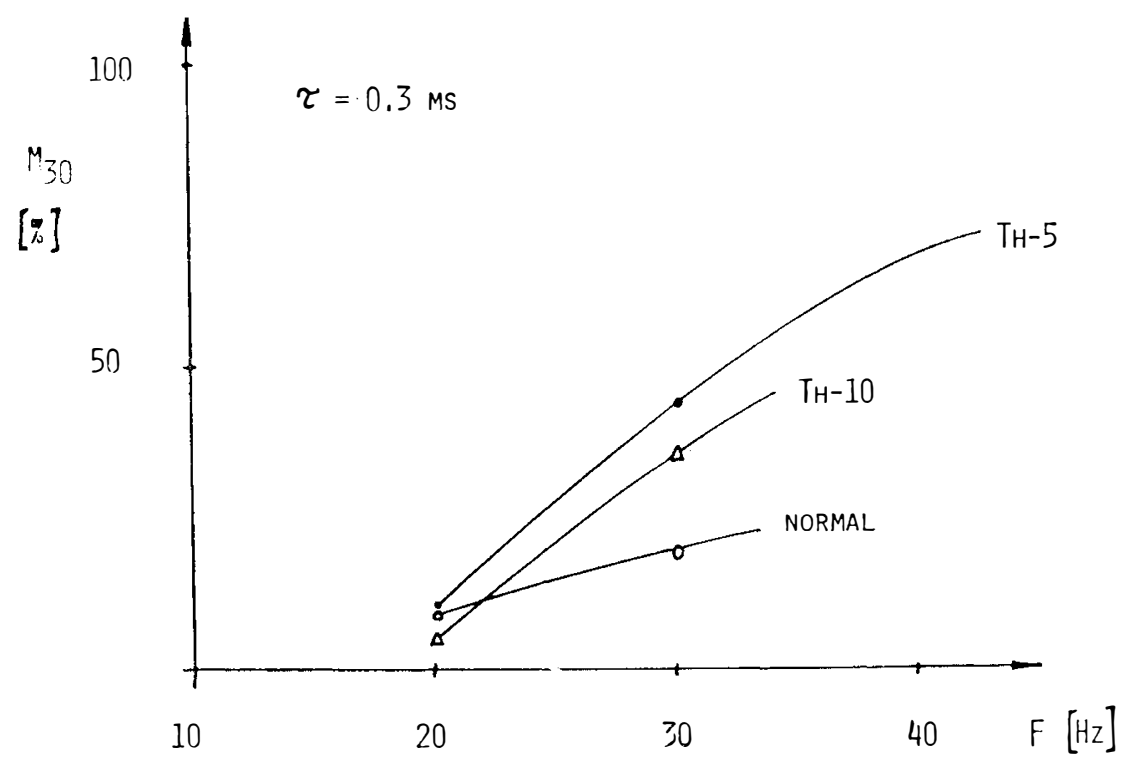

FIG. 3

The joint torque decrease at different stimulation frequencies plotted for $\mathrm{T}_{5}$ and $\mathrm{T}_{\mathrm{o}} \mathrm{O}$ paraplegic patients and normal subject. 
muscle. The muscle force that can be obtained by the low-frequency stimulation is somewhat smaller with respect to the high-frequency stimulation.

Once the muscle torques have been recognised to be sufficient to perform some functional tasks we tried to maintain the patients in the standing position. Both patients (P. Z. (T5) and P. K. (Tio)) were able to stand erect by use of electrically stimulated and retrained muscles at the end of the programme for more than one hour. At the beginning of the programme the standing time in the range of few minutes. The erect standing was provided by stimulating only knee extensors and secured in the parallel bars (Fig. 4). For better posture other muscles have to be added, like hip extensors and abductors. Some preliminary experiments of generating primitive walking patterns were performed with both patients in parallel bars. Knee extensors were stimulated during double phase and hip abductors, hip flexors and ankle dorsi flexors during the swing phase of walking.

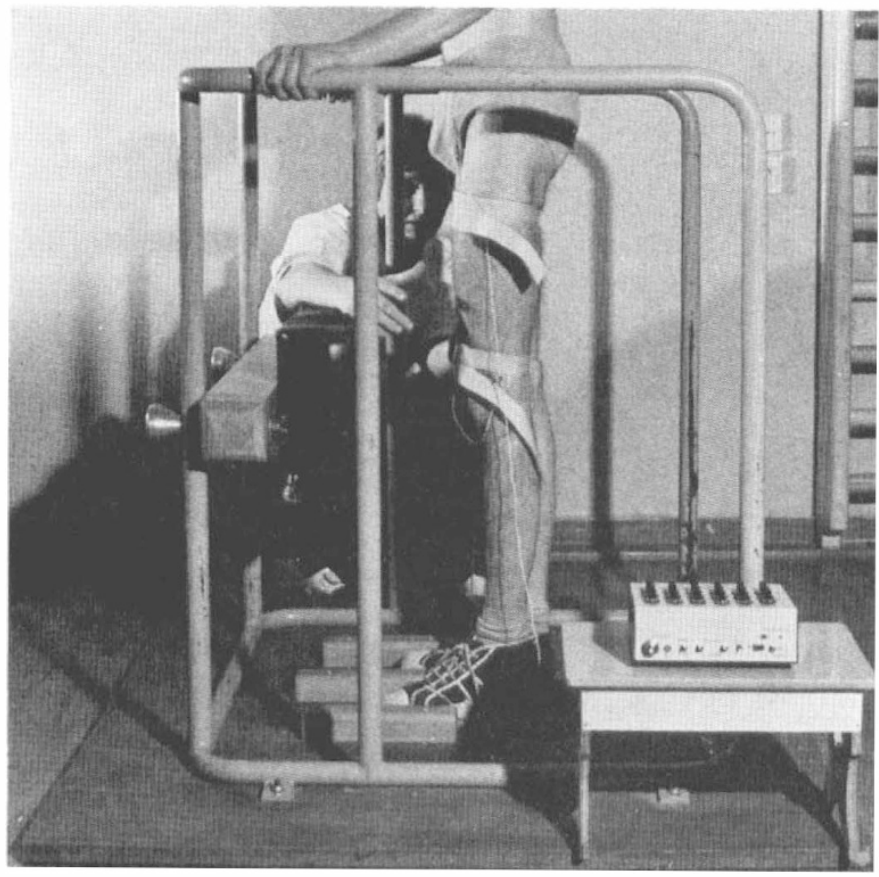

FIG. 4

Paraplegic patient P. Z. (T5) standing in parallel bars with the aid of stimulated knee extensors.

\section{Discussion}

The results obtained clearly demonstrate that the surface electrical stimulation represents a potential tool for a more effective rehabilitation of paraplegic patients. In the further research we shall investigate the possibilities where the surface stimulation can be introduced in daily activities of the paraplegic patient's life. On the other side, we believe that for orthotic use the implanted electrodes should be introduced. It is clear to us that at this point of our research more knowledge has to be collected, particularly regarding the best training procedures, biomechanical 
problems related to the control of patients' balance while standing, generation of corresponding control and bio-feedback signals. Finally, it can be definitely stated that functional electrical stimulation could be a powerful method for effective, and natural-like walking of paraplegic patients.

\section{RÉSUMÉ}

L'influence de la stimulation électrique superficielle chronique sur les muscles paraplegiques est traitée dans l'article. Les résultats de l'altération des propriétés des muscles sont critiquement comparés avec les resultats des recherches précédentes. L'optimisation des paramètres de la stimulation, la procédure du entraînement des muscles atrophiés et le fonctionnement des muscles renforcés pendent être debout et pendant la marche sont les sujets aussi discutés dans cet article.

\section{ZUSAMMENFASSUNG}

In dieser Betrachtung ist angeführt lediglich täglich aplizierte Elektrostimulation durch Haut-Elektroden sowie deren Beeinflussung auf die Muskulatur seitens der paraplegischen Patienten. Auf diese Weise erreichte Veränderungen der Muskulatur und deren Eigenschaften sind kritisch verglichen mit publizierten Daten verschiedener Autoren. Die Optimisation ist erörtert in folgenden Punkten: Es handelt sich um elektrische Stimulation sowie um das Training-Verfahren mit gleichzeitiger Anwendung der durch Elektrostimulation verstärkten Muskulatur, wobei man ein einfaches Stehen sowie ein primitives Gehen erreichen kann.

\section{REFERENCES}

Brindley, G. S., Polkey, C. E. \& Rushton, D. N. (1979). Electrical splinting of the knee in paraplegia. Paraplegia, 16, 428.

KRALJ, A. \& GROBELNIK, S. (I973). Functional electrical stimulation of paraplegic patients - a new hope for paraplegic patients. Ball. Prosthet. Res., 10-20, 75.

KRALJ, A., BAJD, T., TURK, R. \& Benko, H. (I979). Paraplegic patients standing by functional electrical stimulation. XII International Conference on Medical and Biological Engineering, Jerusalem. To be given in August.

Peckham, P. H., Mortimer, J. T. \& Marsolais, E. B. (1976). Alternation in the force and fatigability of skeletal muscles in quadriplegic humans following exercise induced by chronic electrical stimulation. Clinical Orthopaedics, 114, 326. 